\title{
La Balma de la Vall (Montblanc, Tarragona): ocupaciones de corta duración durante el Paleolítico superior final en las Montañas de Prades*
}

\author{
Balma de la Vall (Montblanc, Tarragona): Short-term occupations during Final Upper \\ Palaeolithic at the Prades Mountains
}

\author{
María Soto $^{a}$, Juan Ignacio Morales ${ }^{b}$, Juan Luis Fernández-Marchena ${ }^{b}$, José Ramón \\ Rabuñal $^{c}$, Palmira Saladiéc, d, e, f, Gala García-Argudo ${ }^{b}$, Diego Lombao ${ }^{c}$, Miguel Soares ${ }^{c}$, \\ Ramón Viñas $^{c}$ y Josep Vallverdúc, d
}

\section{RESUMEN}

Este artículo presenta los trabajos realizados en el yacimiento de la Balma de la Vall (Montblanc, Tarragona). Las primeras excavaciones, a inicios de los 1980, identificaron distintos niveles de ocupación humana relacionados con el Paleolítico superior final. Entre los años 2011-2013 la excavación se reemprendió con los objetivos de definir la sucesión arqueo-estratigráfica, obtener dataciones absolutas, y caracterizar el tipo de ocupaciones que generaron los conjuntos arqueológicos. De esta forma, hemos identificado una secuencia que comprende tres niveles arqueológicos, con dataciones que los asocian al XV milenio cal BP, y por tanto al Magdaleniense superior final. Los análisis de las materias primas líticas empleadas, la composición de los conjuntos y las secuencias de reducción permiten definir las ocupaciones como cortas o de baja intensidad. La Balma de la Vall constituye así una de las primeras evidencias de ocupación humana de la Cordillera Prelitoral Catalana.

\begin{abstract}
This paper details the fieldwork and multi-disciplinary studies carried out at the site Balma de la Vall (Montblanc, Tarragona). The first interventions, dating from the early 80 's, identified different occupational levels related to Final Upper Palaeolithic. From 2011 to 2013 research recommenced to re-define the archaeo-stratigraphic succession, obtain absolute dates, and characterize the occupational patterns generating the archaeological assemblages. The revised sequence comprises three archaeological levels, dated to the 15th millenium calibrated BP, and therefore associated to the Final Upper Magdalenian. The raw materials exploited, the assemblage composition and reduction sequences, define the occupational pattern as short duration or low intensity one. Balma de la Vall represents one of the first examples of human occupation of the Catalan Prelittoral Range.
\end{abstract}

* Estos trabajos se enmarcan en el proyecto 2014/100574 de la Generalitat de Cataluña, el grupo de investigación SGR2014/901 (AGAUR) y los proyectos CGL2016-80000-P y CGL2015-65387-C3-1-P (MINECO/FEDER) y han sido financiados en parte por el Ayuntamiento de Montblanc. M.S. es beneficiaria de un contrato Post-Doctoral, SSHRC (Canadá) asociado al proyecto "Stone Tools, Diet and Sociality", J.I.M. de uno Post-Doctoral Juan de la Cierva-Formación; J.L.F-M de una beca FPI del MINECO/FSE (BES-2015-074931) vinculada al proyecto HAR 2014-55131; G.G-A. de una beca Pre-Doctoral APIF y D.L. de una beca Pre-Doctoral AGAUR/FSE (2018-FI-B-00364).

a Dept. of Anthropology and Archaeology. University of Calgary. Calgary. Alberta. T2N 1N4. Canada. Correo e.: sotoquesadamaria@gmail.com https://orcid.org/0000-0003-4154-5384

b Seminari d'Estudis i Recerques Prehistòriques (SERP), Secció de Prehistòria i Arqueologia. Facultat de Geografia i Història. Universitat de Barcelona. C/ Montalegre 6-8. 08001 Barcelona. España. Correo e.: jignacio.morales@gmail.com https://orcid.org/0000-0002-8253-414X; juanl.ferna@gmail.com https://orcid.org/0000-0003-3023-1494; gala.garcia.argudo@gmail.com https://orcid.org/0000-0003-3857-7836

Institut Català de Paleoecologia Humana i Evolució Social (IPHES). C/Marcel·lí Domingo s/n (Edifici W3). Campus Sescelades. 43007 Tarragona. España. Correo e.: jr.rabunal@gmail.com https://orcid.org/0000-0002-5757-1897; psaladie@iphes.cat http://orcid.org/0000-0002-17308461; diego.lombao@gmail.com https://orcid.org/0000-0001-8991-7947; miguel.soares.remiseiro@gmail.com https:/orcid.org/0000-0002-0256-2221; rvinas@iphes.cat https:/orcid.org/0000-0003-2568-4325; jvallverdu@iphes.cat https:/orcid.org/0000-0002-3177-3263

$\mathrm{d}$ Àrea de Prehistòria, Universitat Rovira i Virgili (URV), Campus Catalunya, Avinguda de Catalunya 35, 43002 Tarragona, España.

e GQP-CG, Grupo Quaternário e Pré-História do Centro de Geociências (uI\&D 73 - FCT), Maçao, Portugal.

${ }^{\mathrm{f}}$ Unidad asociada al CSIC, Departamento de Paleobiología, Museo Nacional de Ciencias Naturales (MNCN), Consejo Superior de Investigaciones Científicas (CSIC), Calle José Gutiérrez Abascal, 2, 28006 Madrid, España.

Recibido 19-V-2017; aceptado 10-IX-2017.

Copyright: (C) 2018 CSIC. Este es un artículo de acceso abierto distribuido bajo los términos de la licencia de uso y distribución "Creative Commons Reconocimiento 4.0 Internacional" (CC BY 4.0). 
Palabras clave: Industria lítica; Materias primas; Península Ibérica; Paleolítico superior final; Magdaleniense.

Key words: Lithic Technology; Raw materials; Tarragona; Final Upper Palaeolitihic; Magdalenian.

\section{INTRODUCCIÓN}

Este artículo presenta los resultados estratigráficos, cronológicos, tecnológicos y zooarqueológicos de las campañas de excavación (2011 a 2013) en la Balma de la Vall (Montblanc, Tarragona). Su motivación principal es dar a conocer el yacimiento y caracterizar la secuencia documentada, aportando información sobre la variabilidad ocupacional y las dinámicas de movilidad y gestión del territorio durante las fases finales del Paleolítico superior. Este punto será de vital importancia para una futura interpretación regional de las dinámicas económicas y demográficas de los cazadores-recolectores en el NE de la Península Ibérica, especialmente en el territorio litoral y prelitoral comprendido grosso modo en torno a la cuenca distal del río Ebro.

Esta área constituye un caso ideal para plantear, a escala regional, la caracterización integral del comportamiento de los grupos humanos del Tardiglaciar. La intensidad de la investigación durante los últimos 30 años ha proporcionado un importante corpus de datos y yacimientos para abordar cuestiones más allá de la mera caracterización y comparación tecno-tipológica de los conjuntos. Los trabajos desarrollados tanto en el valle del río Montsant (Vilaseca 1949; Fullola 1983-1984; Domènech 1998; García-Argüelles, Adserias et al. 1992; García-Argüelles 2004; Fullola y García-Argüelles 2006; García-Argüelles, Nadal y Fullola 2005; García-Argüelles, Fullola et al. 2013; García-Argüelles, Nadal et al. 2014) como en los valles de los ríos Francolí y Gaià (LAUT 1992; García et al. 1996, 1997; Angelucci 2003; Vaquero, Allué et al. 2005; García y Vaquero 2006; García Catalán 2007; García Catalán, Vaquero et al. 2009; Fontanals et al. 2009; Vaquero, Alonso et al. 2012; García Catalán, Gómez de Soler et al. 2013; Morales et al. 2013; Soto et al. 2014) ponen de manifiesto una intensa ocupación del territorio coincidiendo con la mejora climática del GI-1, entre 14 y $15 \mathrm{ka}$ cal BP.

Esta ocupación coincide con el final del GS-2 o Dryas antiguo y ello es evidente observando la distribución de las dataciones absolutas (Morales et al. 2012: 25). En este sentido destaca la homogeneidad de las principales secuencias regionales, como la del Abric del Filador, el Molí del Salt, la Cativera o el yacimiento inédito de la Cova de les Borres ${ }^{1}$. En to-

\footnotetext{
1 La Cova de les Borres se localiza en el término municipal de La Febró, comarca del Alt Camp (Tarragona). El yacimiento, actualmente en excavación por parte del IPHES, presenta diferentes niveles de ocupación humana comprendidos grosso modo entre los 15 y los $11 \mathrm{ka}$ cal BP.
}

das ellas se observa una sincronía en el origen de las ocupaciones (tránsito GS-2/GI-1), su perduración hasta bien entrado el Holoceno y la falta de las mismas durante el GS-1 o Dryas reciente y el Pre-Boreal. Además de estos asentamientos, con una dinámica de ocupación continua durante gran parte del Tardiglaciar, otros tienen un patrón de ocupación más esporádico como l'Hort de la Boquera, Picamoixons o la Balma de la Vall. Aquí las ocupaciones se asocian a horquillas cronológicas más constreñidas, con una perduración no tan significativa.

La variabilidad diacrónica de los patrones de ocupación de los distintos yacimientos permite estudiar las dinámicas de asentamiento de los mismos y su función. Este primer trabajo sobre la Balma de la Vall ahonda en esta línea y diseña una interpretación de los datos dirigida a la caracterización del tipo de ocupaciones que generaron los horizontes arqueológicos excavados.

\section{LOCALIZACIÓN}

La Balma de la Vall (término municipal de Montblanc, Tarragona) se encuentra en las coordenadas geográficas (ETRS89) UTM-31 N 344925.0 E (x), 4579681.0 N (y) (Fig. 1). Se sitúa en el margen izquierdo del Barranco de la Vall, un cauce tributario que recorre el sector nororiental de las Montañas de Prades y que a $2 \mathrm{~km}$ al sur del yacimiento se incorpora al curso principal del río Francolí. Éste barranco conforma uno de los ejes de comunicación natural más significativos del entorno, uniendo el corazón de las Montañas de Prades con uno de los principales valles fluviales de la cadena costera catalana.

Los dos abrigos que conforman la Balma de la Vall se abren en un banco de areniscas rojas, a techo del Buntsandstein $^{2}$ (IGME 1975). El abrigo superior tiene unas dimensiones de $21 \times 10 \mathrm{~m}$ que en el inferior se reduce a $10 \times 7 \mathrm{~m}$ (Fig. 2).

\section{ANTECEDENTES}

Salvador Vilaseca (1953: 297-313) publica la primera mención al potencial arqueológico del Barranco de la Vall. Destaca la práctica ausencia de cerámica y la existencia de una industria de lascas y láminas para la que no propone atribución crono-cultural.

En 1975 miembros de la Sección Arqueológica del Museu-Arxiu de Montblanc i Comarca descubren los dos abrigos que conforman la Balma de la Vall. En 1976 tuvo lugar una campaña de prospección y recogida de los materiales superficiales del yacimiento para

\footnotetext{
${ }^{2}$ Mapa Geológico de España 1:50000. Hoja 417. 33-16 Espluga del Francolí. IGME. Serie Magna. Madrid, 1975.
} 

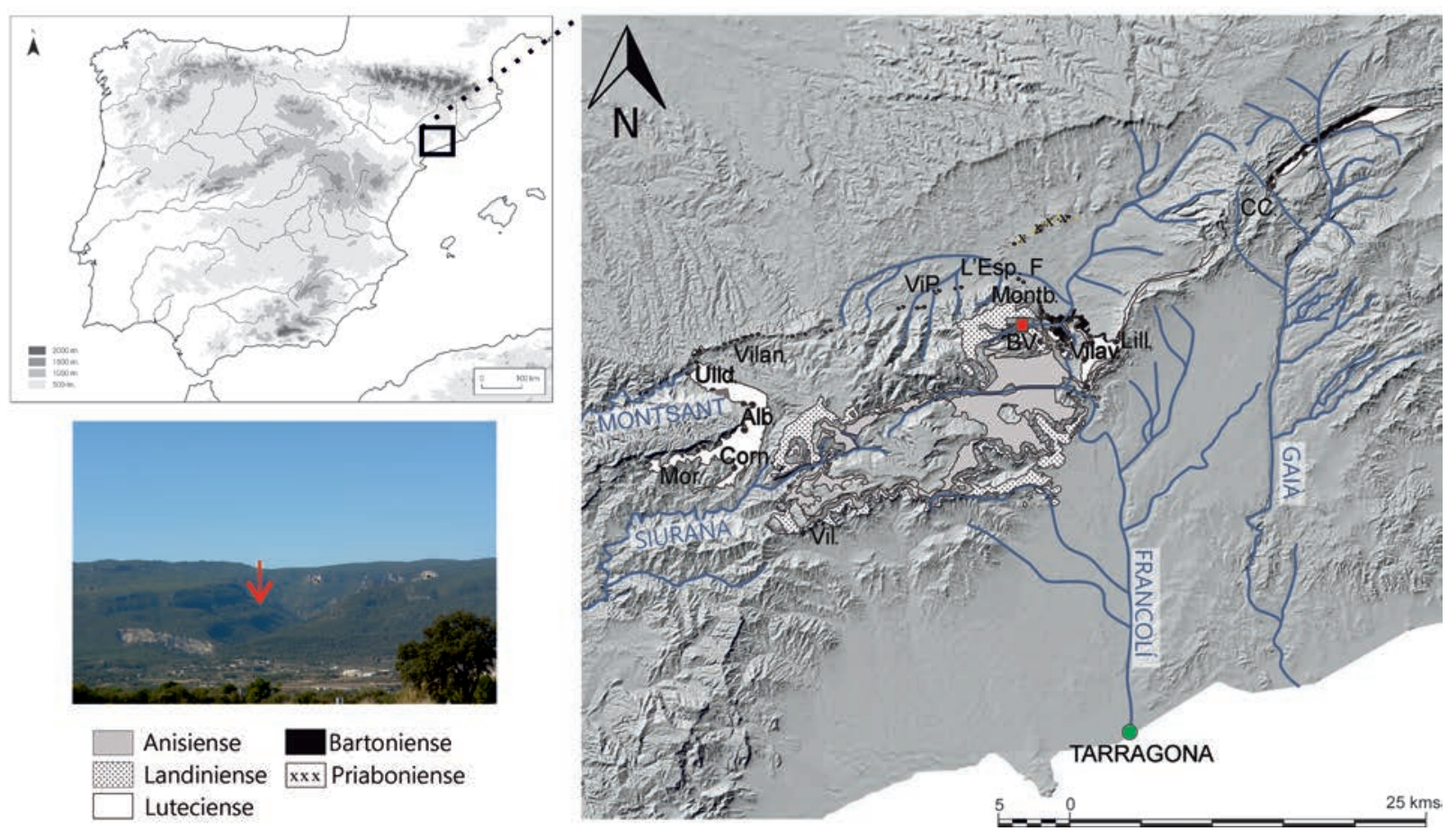

Fig. 1. Localización de la Balma de la Vall (Montblanc, Tarragona) (BV) ¿sobre el valle del río Montsant y respecto a las unidades geocronológicas con sílex en posición primaria regionales: Mor. Morera del Montsant; Ulld. Ulldemolins; Corn. Cornudella; Vilan. Vilanova; Alb. Albarca; Vil. Vilaplana; ViP. Vimbodí i Poblet; L’Esp. F. L'Espluga del Francolí; Montb. Montblanc; Vilav. Vilaverd; Lill. Lilla; CC. Cabra del Camp (en color en la edición electrónica).

evaluar su potencial. Siguieron dos campañas de excavación, 1979 y 1980, dirigidas por Matíes Solé, que intervino en tres zonas: el abrigo superior (LV1), un área intermedia entre los dos abrigos correspondiente a la zona distal del cono de sedimentación del abrigo superior (LV2), y el abrigo inferior (Taller o LV3).

En LV1 y LV2 se recuperó abundante material cerámico asociado al Bronce medio. En LV3 se excavaron $22 \mathrm{~m}^{2}$ definiendo tres niveles con material lítico y fauna: "Estrato 1", formado por tierra vegetal quemada debido a una carbonera subactual, con sílex y fragmentos de cerámica a mano; "Estrato 2", un nivel estalagmítico con restos arqueológicos y "Estrato 3", un nivel de arcillas rojas compactas con numerosos restos arqueológicos (Adserias y Solé 1994).

Las piezas líticas de los "Estratos 2" y "3" de LV3, a falta de dataciones absolutas, se atribuyeron al Paleolítico superior final por su similitud tipológica con los materiales de Sant Gregori (Falset) y de la Font Voltada (Barberà de la Conca) (Adserias y Solé 1994).

El registro faunístico, aunque escaso, permitió identificar restos de Capra pyrenaica, Cervus elaphus, Lynx sp., Oryctolagus cuniculus y Bovidae sp. (Nadal 1994).

Finalmente, en 2011 se inició un nuevo ciclo de investigación desde el IPHES y el Museu-Arxiu de Montblanc i Comarca. Los trabajos, planteados como ampliación del proyecto 2014/100574 "Evolución paleoambiental y poblamiento prehistórico en las cuencas de los ríos Francolí, Gaià, Siurana y rieras del Campo de Tarragona", fueron también incluidos en dos tesis doctorales sobre el Paleolítico superior de la zona (Morales 2015; Soto 2015). Esta nueva excavación amplió el conocimiento sobre la movilidad y la gestión de recursos durante el Paleolítico superior final, teniendo también en cuenta los datos de yacimientos como el Molí del Salt (Vimbodí i Poblet) (Vaquero 2004; García Catalán 2007; Vaquero et al. 2012; García Catalán et al. 2013) la Cativera (El Catllar) (Fontanals et al. 2006; Morales et al. 2013) o la Cova de les Borres (La Febró) (Morales 2015; Soto 2015; Soto et al. s. f.).

Entre 2011 y 2013 se realizaron tres campañas de excavación en el abrigo inferior del conjunto de $\mathrm{La}$ Vall, afectando a una superficie de $15 \mathrm{~m}^{2}$ del sector más occidental. Todo el material de más de $1 \mathrm{~cm}$ se situó por coordenadas cartesianas absolutas. Los restos de dimensiones inferiores pasaron a bolsas de nivel según rangos de cota de $5 \mathrm{~cm}$, cuadros y niveles correspondientes. Además, el sedimento fue tamizado en seco en el propio yacimiento, recuperando los materiales de menor tamaño. Este estudio sólo considera el material coordenado y/o incluido en las bolsas. 


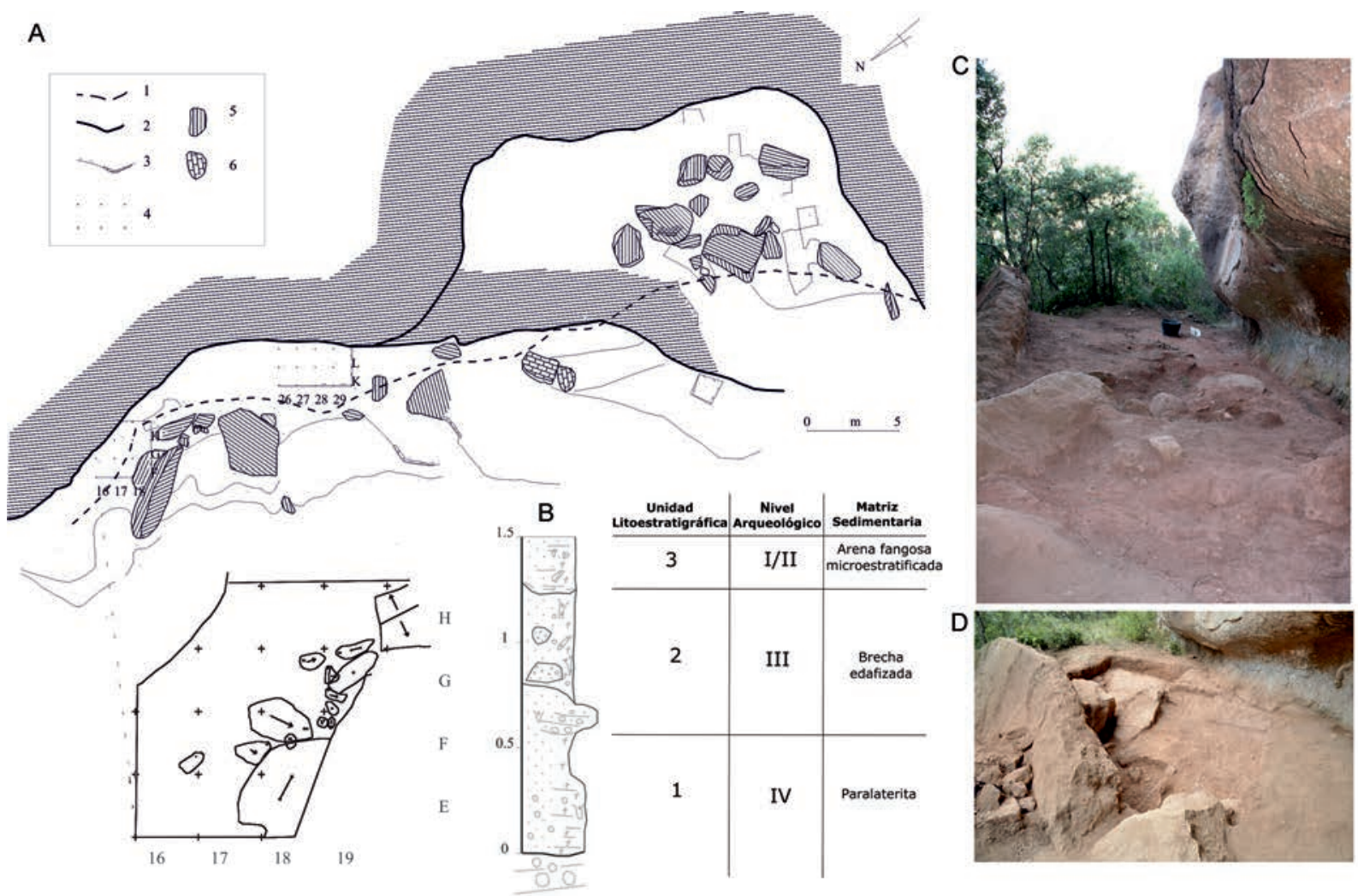

Fig. 2. Sector occidental del abrigo inferior de la Balma de la Vall, campaña de 2012: A. Planimetría: 1. línea de visera; 2. pared; 3. cresta topográfica; 4. superficie de excavación; 5. bloque de arenisca; 6. bloque de caliza. B. Perfil litoestratigráfico. C. y D. Vistas de la superficie del yacimiento durante los trabajos de excavación (en color en la edición electrónica).

\section{SECUENCIA ESTRATIGRÁFICA Y CRONOLOGÍA}

El depósito sedimentario de la Balma de la Vall se caracteriza por una composición homogénea de areniscas triásicas en tamaños de bloques, arenas y fango, propias de la disgregación de la pared del abrigo. Esta disgregación incorpora además costras ferruginosas, gravas finas y fragmentos de cuarcitas y cuarzos de la formación original.

Los análisis han permitido definir una secuencia sedimentaria (Fig. 2) formada de techo a muro por tres unidades lito-estratigráficas (Vallverdú et al. 2014):

Unidad 3 (unos $25 \mathrm{~cm}$ de grosor): arenas y fangos mal estratificados con base erosiva en forma de surco. La estratificación de estos sedimentos apunta a dos procesos: 1) formación de un surco erosivo causado por la línea de goteo de la cornisa y su posterior relleno por arena y fango microestratificado; y 2) existencia de procesos de bioturbación y perturbación mecánicaantrópica, que erosionan e incorporan materiales de la unidad 2 subyacente.
Unidad 2 (50 $\mathrm{cm}$ de grosor máximo): brecha edafizada, donde se han definido hasta tres procesos sedimentarios: 1) caída gravitacional de megabloques, bloques y arenas; 2) costras sedimentarias de escorrentía formadas por arenas y fangos agregados; y 3) horizonte formado por agregados minerales granulares.

Unidad 1 (75 cm de grosor): base de la secuencia estratigráfica, en contacto con la roca caja, está formada por la alterita de la arenisca, producto a la meteorización de la superficie de la roca.

Se han distinguido cuatro horizontes o niveles arqueo-estratigráficos (Fig. 3):

Nivel I: nivel a techo de la superficie de la Unidad 3, compuesto por arenas y fangos rojos granulados con evidencias de bioturbación y remociones subactuales, que lo han descartado para este estudio. Tiene abundante material cerámico, instrumentos líticos, carbones y escasa fauna.

Nivel II: definido en la base de la Unidad 3, y formado por arenas rojas granulares muy compactadas. Presenta material lítico y escasos restos faunísticos. 
Nivel III: definido en la Unidad 2 y compuesto por areniscas de disgregación de la pared con megabloques. Los materiales líticos tallados son mayoritarios frente a los restos faunísticos. De este nivel proceden la mayoría de los materiales arqueológicos recuperados.

Nivel IV: definido bajo los megabloques del nivel III, su matriz es arenosa y de coloraciones grisáceas. La industria lítica es puntual.
La caracterización cronológica de las ocupaciones ha sido un proceso complejo por la mala preservación general de los restos faunísticos y la escasez de carbones. Estos condicionantes propiciaron una primera datación absoluta mediante Termoluminiscencia sobre un sílex con evidencias de alteración térmica del nivel III. Esta datación situó las ocupaciones entre 17 ka y $14.5 \mathrm{ka}$ BP (Tab. 1). Un intento de fechar el nivel II
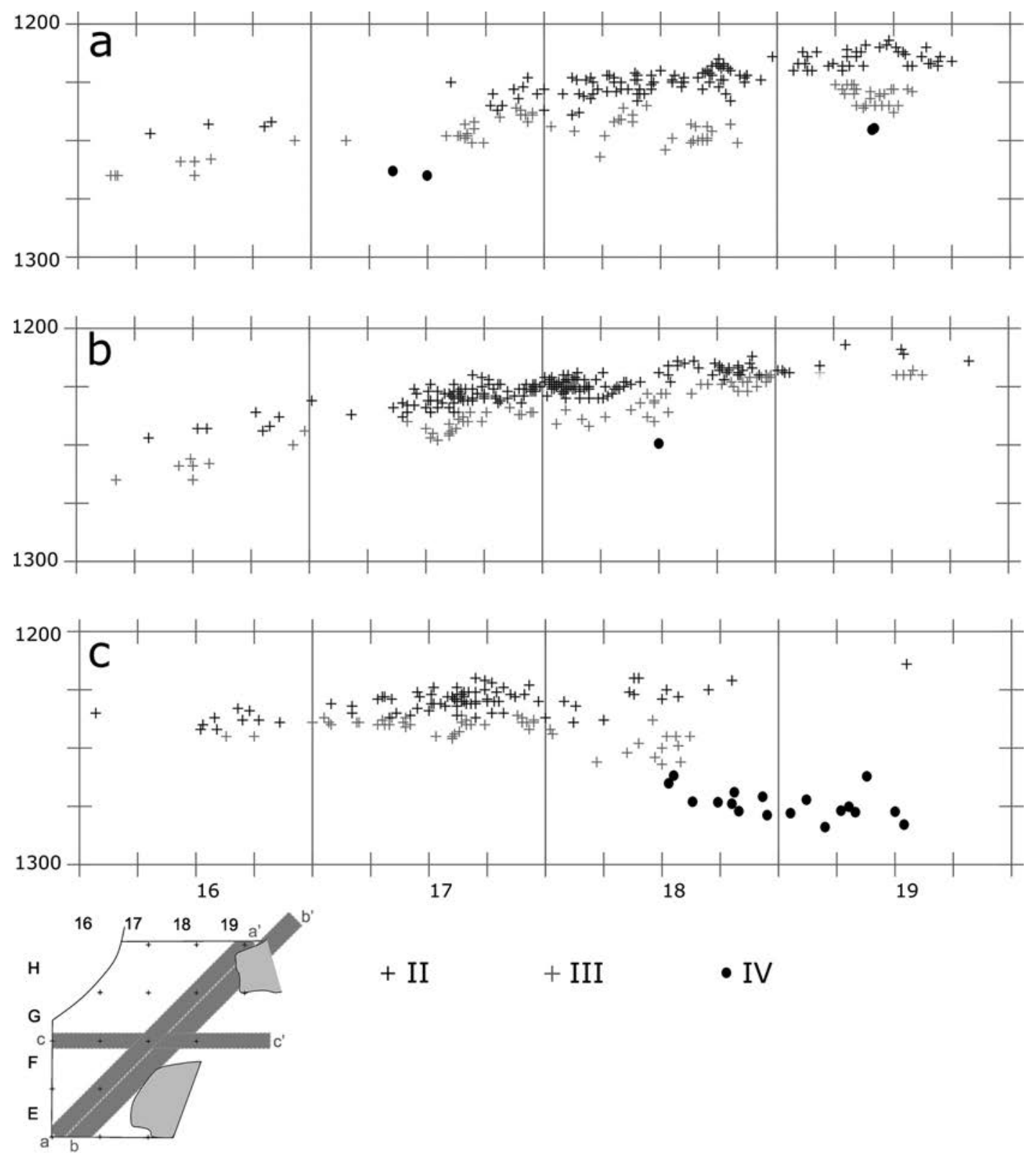

Fig. 3. Sector occidental del abrigo inferior de la Balma de la Vall, campañas 2011-2013. Proyecciones verticales de todo el material arqueológico coordenado en tres de los niveles arqueo-estratigráficos distinguidos. 


\begin{tabular}{|c|c|c|c|c|c|c|c|}
\hline Nivel & Muestra & ID & Técnica & Años C14 & DE & Años Calendario & $\begin{array}{c}\text { Años Calendario } \\
\text { (cal BP 2s) }\end{array}$ \\
\hline III & Sílex quemado & MADN-6029BIN & TL & & & $17229-14449$ & \\
\hline III & Carbón & Beta-361901 & C14-AMS & 12340 & 40 & & $14510-14310$ \\
\cline { 5 - 7 } & & & & & & & $14260-14110$ \\
\hline
\end{tabular}

Tab. 1. Dataciones absolutas del sector occidental del abrigo inferior de la Balma de la Vall. ID. Código del laboratorio; DE. Desviación estándar.

a partir de una muestra de fauna proporcionó fechas históricas. Posteriormente, la recuperación de algunos carbones también en el nivel III permitió una datación por C14 AMS que refinó la cronología entre $14.5 \mathrm{y}$ $14 \mathrm{ka}$ cal BP.

De esta forma, el nivel III se sitúa a inicios del GI-1e, al final del Magdaleniense superior. Esta cronología, coherente con la adscripción original del conjunto Paleolítico superior final realizada por Adserias y Solé (1994), es una de las evidencias más antiguas de ocupación humana en las Montañas de Prades hasta el momento.

\section{LAS OCUPACIONES MAGDALENIENSES}

\subsection{Industria lítica}

El conjunto está formado por un total de 1582 elementos. El nivel III es el conjunto de mayor entidad (1143 restos), seguido del nivel II (392) y del nivel IV (47).

El sílex es la principal litología explotada: más del $97 \%$ en los tres niveles. De forma muy puntual se documenta también el cuarzo, la cuarcita, la caliza y el esquisto.

El conjunto se ha estudiado desde una doble perspectiva: a) caracterizando las materias primas para determinar su origen y los patrones de captación y b) mediante análisis tecno-tipológico para profundizar en el comportamiento técnico y en la gestión de las secuencias de reducción.

\subsubsection{Materias primas}

Se han analizado las características macro y microscópicas del conjunto mayor de $1 \mathrm{~cm}$ a fin de establecer su procedencia, las estrategias de captación y las dinámicas de movilidad de los cazadores-recolectores (Binford 1980; Kelly 1983, 1992).

La descripción de visu, y mediante lupa binocular, de los rasgos macroscópicos identificó diferentes tipos silíceos y variedades macroscópicas. Después el análisis petrográfico a partir de láminas delgadas determinó la textura y mineralogía de sus componentes (Bathrust 1975; Kendall 1979; Sonnefeld 1979; Arbey 1980; Tucker y Wright 1990; Boggs 2009).

Los resultados han sido comparados con la colección lítica de referencia del IPHES que incluye, entre otras, muestras de las silicificaciones del entorno de las Montañas de Prades ${ }^{3}$. El muestreo de 56 afloramientos primarios asociados a cinco unidades geocronológicas (Fig. 1) ha generado más de un centenar de muestras de mano, 60 láminas delgadas no cubiertas, y una serie de microanálisis complementarios (MEB, EDS, DRX, $\mu$-DRX y espectroscopia Raman) sobre muestras representativas de cada tipo silíceo (Soto et al. 2014; Soto 2015).

Con base en esta caracterización petrológica se han descrito ocho variedades morfoscópicas de sílex, agrupadas en cuatro tipos silíceos (AC1). Todos ellos muestran convergencias con tipos de la colección de referencia. Los principales tipos identificados son sílex de Tossa, Morera, Maset y Vilaplana, cuyos rasgos principales, representación en el registro y localización en el territorio resumimos.

1. Sílex de Tossa: edad Bartoniense, localizado principalmente en afloramientos del Barranc de la Tossa, al SO de la localidad de Montblanc y a unos $2 \mathrm{~km}$ en línea recta del Barranco de la Vall. A veces se describe en el entorno de Vilaverd, Lilla, a 4-5 km, y en Cabra del Camp y Ulldemolins, a más de $20 \mathrm{~km}$ del yacimiento. Es el soporte de 343 restos. Los análisis petrográficos definen dos variedades morfoscópicas: Tossa 1, la más abundante, tiene colores grises con superficies translúcidas y mates, y una textura al tacto fina-muy fina. Tossa 2 presenta colores negros, superficies opacas y una textura macroscópica finamuy fina (Tab. 2).

2. Sílex de Maset: edad Luteciense, aparece sobre todo al NO de Ulldemolins, a $25 \mathrm{~km}$ del yacimiento, aunque también ha sido descrito en Morera del Monsant, Cornudella del Montsant y Vilanova de Prades, a 24-27 km, y en l'Espluga del Francolí y Lilla, a unos

\footnotetext{
3 Soto, M.; Gómez de Soler, B. y Vallverdú, J.: "LithIPHES: a lithic reference collection for the NE Iberian Peninsula Prehistory". $11^{\text {th }}$ International Symposium on Knapable Materials, 7-12 th November 2017. Book of Abstracts.
} 


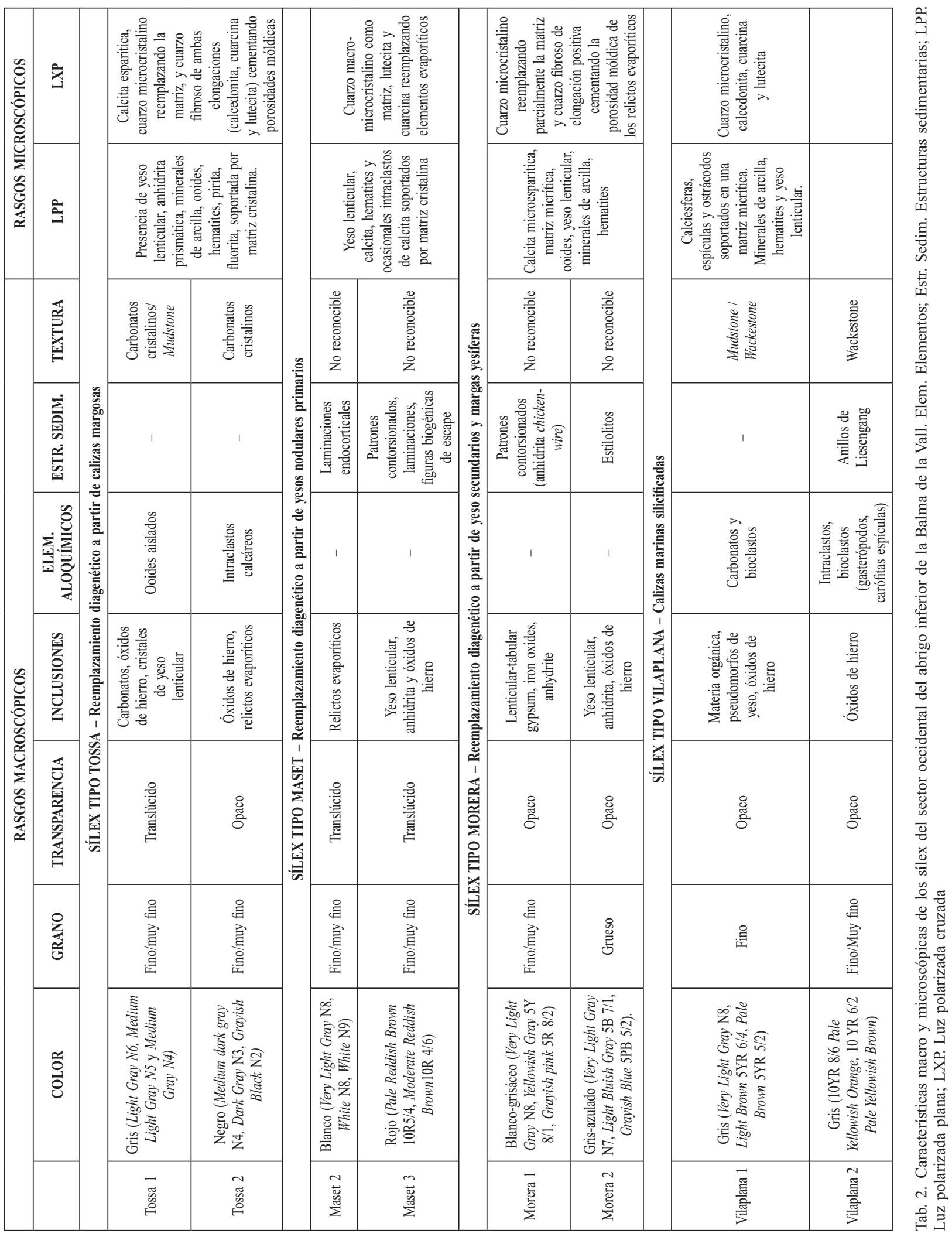

Trab. Prehist., 75, N. ${ }^{\circ} 2$, julio-diciembre 2018, pp. 270-286, ISSN: 0082-5638 https://doi.org/10.3989/tp.2018.12215 
3-5 km. Es la materia prima de 394 restos. Se asocia a las variedades: Maset 2 de tonalidades blanquecinas y Maset 3 de coloraciones rojizas. El aspecto de ambas es mate y translúcido con textura al tacto fina-muy fina (Tab. 2).

3. Sílex de Morera: edad Luteciense, se localiza principalmente en Morera del Montsant, a $27 \mathrm{~km}$ del yacimiento. También se ha descrito en afloramientos ubicados en Cornudella, Albarca y Ulldemolins, a $23-21 \mathrm{~km}$, y en las localidades de Poblet y Vilaverd, a 7 y $2 \mathrm{~km}$ respectivamente. Es el soporte de 71 restos con ciertas convergencias con Morera 1 de tonalidades blanquecinas y Morera 2 con tonalidades grisáceo-azuladas. Las superficies de ambas son mates y opacas con texturas al tacto heterogéneas, que varían de gruesas a finas/muy finas, y frecuentes fisuras (Tab. 2).

4. Sílex de Vilaplana: edad Ladiniense y afloramiento principal en Vilaplana, a $20 \mathrm{~km}$ del abrigo. Su presencia es continua pero dispersa a lo largo de toda la formación, localizándose algunos nódulos en las localidades de Arbolí, Mont-Ral y La Riba, distantes de 8 a $5 \mathrm{~km}$, y en el mismo barranco de la Vall (Virgili 1958). Es el soporte menos utilizado con 10 restos. Se vincula a Vilaplana 1 de coloraciones grisáceas, opaco y textura fina/muy fina al tacto. Vilaplana 2 es una variedad xiloide gris, con anillos de Liesengang, superficies mates, opacas, y una textura muy fina al tacto (Tab. 2).

La alteración total de las superficies del material por pátina o alteración térmica supera el $40 \%$ en los tres niveles arqueológicos.
Las variedades Tossa 1, Maset 2 y Maset 3 son las más utilizadas como soporte de los instrumentos, sobre todo de núcleos y retocados. La presencia del resto de materias primas puede considerarse esporádica. Es mayoritaria en productos de talla y está casi ausente en núcleos y retocados, salvando las variedades Vilaplana 1 y Morera 1 en el nivel III (Tab. 3).

\subsubsection{Secuencias de reducción}

La representación de las diferentes categorías estructurales en los tres niveles es muy similar (Tab. 4). En general, los productos de talla, lascas completas (Base Positiva BP) y fragmentadas (Base Positiva Fragmentada BPF, Fragmento de Base Positiva FBP) dominan los conjuntos. Escasean los retocados (Base Negativa de Configuración BNC) y núcleos (Base Negativa de Explotación BNE). Destaca el porcentaje muy significativo de retocados en el nivel IV. Sin embargo lo limitado del muestreo puede condicionar la sobrerrepresentación.

En todos los niveles los soportes presentan de forma casi exclusiva superficies talonares y dorsales no corticales. Los talones de tipo plataforma dominan y los talones lineales y puntiformes son mínimos. La preparación y delineación más frecuente es el patrón de talones unifacetados rectos. El índice de córtex dorsal oscila entre el $5 \%$ y el $10 \%$ del total, siendo en el nivel III, el más abundante y significativo en cuanto a materiales recuperados, un $6,4 \%$.

\begin{tabular}{|c|c|c|c|c|c|c|c|c|c|c|c|c|c|c|c|c|c|c|}
\hline & \multicolumn{6}{|c|}{ NIVEL II } & \multicolumn{6}{|c|}{ NIVEL III } & \multicolumn{6}{|c|}{ NIVEL IV } \\
\hline & PT & RET. & NUC. & FRAG. & Total & $\%$ & PT & RET. & NUC. & FRAG. & Total & $\%$ & PT & RET. & NUC. & FRAG. & Total & $\%$ \\
\hline AT & 131 & 14 & & 18 & 163 & 45,66 & 342 & 12 & 7 & 61 & 422 & 41,33 & 15 & 1 & & 5 & 21 & 45,65 \\
\hline Tossa 1 & 86 & 7 & 4 & 8 & 105 & 29,41 & 164 & 5 & 8 & 39 & 216 & 21,16 & 15 & 3 & 1 & & 19 & 41,30 \\
\hline Maset 2 & 55 & 3 & & 12 & 70 & 19,61 & 15 & 3 & & 7 & 25 & 2,45 & & 1 & & & 1 & 2,17 \\
\hline Maset 3 & 8 & 2 & & 1 & 11 & 3,08 & 239 & 18 & & 30 & 287 & 28,11 & & & & & 0 & 0,00 \\
\hline Morera 2 & 2 & & & & 2 & 0,56 & 9 & 1 & & 5 & 15 & 1,47 & 1 & & & 2 & 3 & 6,52 \\
\hline Vilaplana 1 & 1 & & & 1 & 2 & 0,56 & 2 & 1 & 2 & 2 & 7 & 0,68 & & & & & 0 & 0,00 \\
\hline Tossa 2 & & & & 1 & 1 & 0,28 & & & & 2 & 2 & 0,19 & & & & & 0 & 0,00 \\
\hline Morera 1 & 2 & & & 1 & 3 & 0,84 & 24 & 17 & & 5 & 46 & 4,51 & 1 & 1 & & & 2 & 4,35 \\
\hline Vilaplana 2 & & & & & & 0,00 & 1 & & & & 1 & 0,10 & & & & & 0 & 0,00 \\
\hline Total & 285 & 26 & 4 & 42 & 357 & & 796 & 57 & 17 & 151 & 1021 & & 32 & 6 & 1 & 7 & 46 & \\
\hline$\%$ & 79,83 & 7,28 & 1,12 & 11,77 & & 100,00 & 77,96 & 5,58 & 1,67 & 14,79 & & 100,00 & 69,57 & 13,04 & 2,17 & 15,22 & & 100,00 \\
\hline
\end{tabular}

Tab. 3. Soportes del sector occidental del abrigo inferior de la Balma de la Vall según variedades morfoscópicas de sílex y categorías ¿estructurales?: PT. Productos de talla, lascas, lascas fragmentadas y fragmentos de lascas; RET. instrumentos retocados; NUC. núcleos; FRAG. Fragmentos. 


\begin{tabular}{|c|c|c|c|c|c|c|c|c|c|c|c|c|c|c|c|c|c|c|c|c|c|c|c|}
\hline & \multicolumn{4}{|c|}{ BNC } & \multicolumn{2}{|c|}{ BNE } & \multicolumn{4}{|c|}{ BP } & \multicolumn{3}{|c|}{ BPF } & & \multicolumn{3}{|c|}{ FBP } & \multicolumn{3}{|c|}{ FRAG } & \multicolumn{3}{|c|}{ Total } \\
\hline & \multicolumn{2}{|c|}{$\mathrm{n}$} & \multicolumn{2}{|c|}{$\%$} & $\mathrm{n}$ & $\%$ & \multicolumn{2}{|c|}{$\mathbf{n}$} & \multicolumn{2}{|c|}{$\%$} & n & & \multicolumn{2}{|l|}{$\%$} & $\mathrm{n}$ & \multicolumn{2}{|c|}{$\%$} & \multicolumn{2}{|l|}{$\mathbf{n}$} & \multicolumn{2}{|l|}{$\%$} & $\mathrm{n}$ & $\%$ \\
\hline II & \multicolumn{2}{|c|}{27} & \multicolumn{2}{|c|}{6,89} & 4 & 1,02 & \multicolumn{2}{|c|}{129} & \multicolumn{2}{|c|}{32,91} & \multicolumn{2}{|c|}{48} & \multicolumn{2}{|l|}{12,24} & 120 & \multicolumn{2}{|c|}{30,61} & \multicolumn{2}{|c|}{64} & 16,33 & \multicolumn{2}{|r|}{392} & 100 \\
\hline III & \multicolumn{2}{|c|}{57} & \multicolumn{2}{|c|}{4,99} & 17 & 1,49 & 36 & & 31,9 & & 110 & & 9,62 & & 336 & & & 258 & & 22,57 & & 1143 & 100 \\
\hline IV & & & & & 1 & 2,13 & 1 & & 29,7 & & 5 & & 10,64 & & 13 & & & 8 & & 17,02 & & 47 & 100 \\
\hline & & & & & & & & & & & & $\mathrm{SC}$ & & & & & & & & & & & \\
\hline & & & & & & c & & & & G & & & D & & D & & R & & & & & & \\
\hline & n & $\%$ & n & $\%$ & n & $\%$ & n & $\%$ & $\mathrm{n}$ & $\%$ & & n & $\%$ & n & $\%$ & $\mathbf{n}$ & $\%$ & $\mathrm{n}$ & $\%$ & $\mathrm{n}$ & $\%$ & $\mathrm{n}$ & $\%$ \\
\hline II & & & 1 & 3,7 & 2 & 7,4 & 5 & 18,5 & 13 & 48 & & 4 & 14,8 & & & 2 & 7,4 & & & & & 27 & 100 \\
\hline III & 2 & 3,5 & 1 & 1,8 & 4 & 7,0 & 11 & 19,3 & 16 & 28 & & 11 & 19,3 & 8 & 14,0 & 1 & 1,8 & 1 & 1,8 & 2 & 3,5 & 57 & 100 \\
\hline IV & & & & & & & 2 & 33,3 & & & & 2 & 33,3 & 1 & 16,7 & 1 & 16,7 & & & & & 6 & 100 \\
\hline
\end{tabular}

Tab. 4. Soportes de sílex del sector occidental del abrigo inferior de la Balma de la Vall según categorías estructurales. BNC Base Negativa de Configuración/retocado; BNE Base Negativa de Explotación/núcleo; BP Base Positiva/lasca; BPF Lasca fragmentada; FBP Fragmento de lasca; FRAG Fragmento. Instrumentos retocados A Abrupto; B Buril; Bc Bec; G Raspadores; LD Lámina de dorso; PD Punta de dorso; R Raedera; S Simple; T Truncadura.

El análisis comparativo de los índices de alargamiento (IA) de lascas completas y retocados identifica la selección intencional de los soportes más alargados para su configuración tanto en el nivel II (BP-II-IA=1,32; BNC-II-IA =1,86), como en el nivel III (BP-III-IA=1,39; BNC-III-IA=2,03). Esta selección es estadísticamente significativa tanto en la media (Mann-Whitney: II, $\mathrm{p}=0,001$; III, $\mathrm{p}=8,359 \mathrm{e}^{-06}$ ) como en la distribución de sus valores (Kolmogorov-Smirnov: II, $\mathrm{p}=0,0009$; III, $\mathrm{p}=0,0002$ ).

Las estrategias de explotación de los núcleos se orientan bien a la producción de lascas, bien de soportes alargados (Fig. 4).

En el nivel II se han recuperado 3 núcleos sobre lasca que jerarquizan la explotación sobre la cara ancha y están organizados para la obtención de soportes alargados. Estos núcleos se explotan a partir de una plataforma de percusión en la zona distal. Además, se han identificado 4 núcleos sobre bloque con reducción bifacial encaminada a la obtención de lascas $(\mathrm{n}=2)$ y unifacial unipolar para la producción de soportes alargados $(n=2)$.

Del nivel III proceden 11 núcleos sobre lasca y 9 sobre bloque. A diferencia de lo documentado en el nivel II, en los núcleos sobre lasca predomina la explotación sobre cara estrecha ( 9 a 2) y se observan series aisladas de explotación unipolar longitudinal. En general, la explotación se realiza desde una plataforma creada en la parte distal del soporte y sobre los bordes laterales, empleando el filo de la lasca como arista guía inicial. La reducción de los núcleos sobre bloque va encaminada a obtener soportes alargados. Cinco muestran una explotación unipolar y dos de ellos evidencias de haber sido reciclados. Los otros cuatro núcleos sobre bloque tienen una explotación ortogonal estructurada en series unifaciales unipolares independientes.

En el nivel IV se ha identificado un único núcleo sobre lasca de tipo raspador carenado.

\subsubsection{Tecno-tipología}

Los niveles II y III, cuya muestra de elementos configurados es mayor, evidencian un patrón relativamente diferente de los grupos dominantes. En el nivel II $(n=26)$ los más representados son los raspadores $(50 \%)$, los denticulados $(19,2 \%)$ y los elementos de dorso $(15,4 \%)$. En el nivel III $(n=57)$ hay un mayor equilibrio entre grupos pero los elementos de dorso dominan $(33,3 \%)$, sobre los raspadores $(28,1 \%)$ y los denticulados (19,3\%). También cuenta con dos truncaduras, ausentes en los otros niveles (Tab. 4).

Los raspadores tienen características similares. Predominan los raspadores frontales sin retoque lateral, configurados sobre láminas y lascas y con el frente situado en la parte distal del soporte (Fig. 4).

Los elementos de dorso en el nivel II se reducen a dos láminas de dorso, una lámina de doble dorso con retoque marginal y una truncada abierta. En el nivel III se han recuperado 19 con gran variabilidad tipológica: láminas de dorso marginal y profundo, láminas de doble dorso, puntas de doble dorso marginal y profundo, puntas de doble dorso y una punta de dorso truncada (Fig. 4). La configuración en ambos niveles se realiza principalmente mediante retoque directo generando morfologías rectilíneas en el caso de las láminas y delineaciones convexas en las puntas de dorso. 


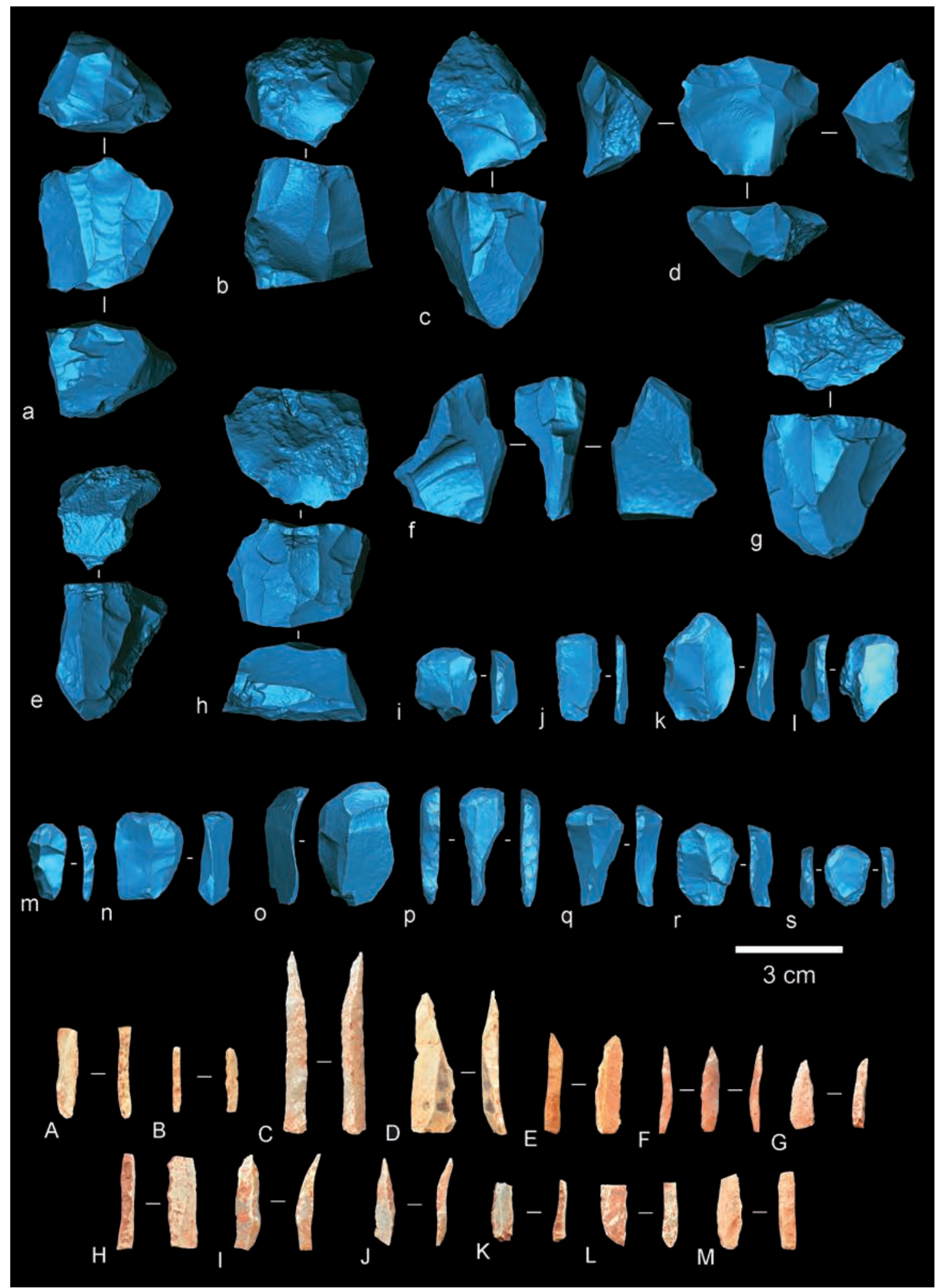

Fig. 4. Industria lítica del sector occidental del abrigo inferior de la Balma de la Vall: a-h núcleos: a-d nivel II, e-h nivel III; i-s. raspadores i-k, nivel II; l-q nivel III, r-s nivel IV; A-M elementos de dorso: A-B nivel II; C-L nivel III, M nivel IV (en color en la edición electrónica). 
En el nivel IV ( $\mathrm{n}=6)$, dominan los elementos de dorso sobre los denticulados y las raederas, suponiendo el $50 \%$ de los configurados. Sin embargo, lo limitado de la muestra condiciona el significado estadístico de esta distribución.

\subsubsection{Gestión y reducción}

Se ha analizado la morfometría de los raspadores de los niveles II y III para determinar su intensidad de uso en base al grado de reducción sufrido desde su configuración hasta su abandono según una metodología ya publicada (Morales, Lorenzo et al. 2015; Morales, Soto et al. 2015; Morales 2016).

Primero se estima la geometría de la morfología original de los soportes usados para la elaboración de los útiles a partir de modelos 3D. Después se calcula la pérdida de volumen producida desde esa morfología original hasta la observada en la fase de abandono. Este cálculo permite construir dos indicadores dirigidos a: 1) obtener la reducción media del conjunto; y 2) estimar una curva de supervivencia de los útiles individuales, basada en la distribución de probabilidad de abandono de los raspadores en un cierto momento de su vida útil.

El primer indicador se obtiene a partir del índice 3DERP (3D-estimated reduction percentage) basado en los valores promediados del conjunto (3DERP=RE/ RE+Tvol) y oscila entre 0 y 1 , siendo 0 no reducción y 1 un estadio teórico de reducción total (para más detalles véase Morales, Lorenzo et al. 2015).

El segundo indicador procede del ajuste del modelo de distribución de los valores individuales de reducción con la distribución de Weibull. Este método estadístico permite modelizar la duración de la vida útil y el riesgo de fallo (o abandono), y se ha empleado en varios estudios tecnológicos que modelizan el descarte de los útiles dentro de un mismo conjunto en diferentes momentos de su vida útil (detalles y aplicaciones en Shott 2002; Shott y Sillitoe 2004; Morales 2016).

Los resultados de los raspadores de los niveles II y III muestran unos valores medios de 3DERP de $0,188 \pm 0,1$, y de $0,215 \pm 0,11$, respectivamente. Éstos indican un nivel de reducción, o aprovechamiento, significativamente bajo, muy cercano a los valores de una muestra experimental donde únicamente se realizó el proceso de configuración inicial de raspadores, y que se situaba en 0,05 $\pm 0,09$ (Morales, Lorenzo et al. 2015).

La distribución de la probabilidad obtenida, a partir del ajuste a la distribución de Weibull, indica una gran homogeneidad en la reducción de todos los raspadores del conjunto, descartando que los valores medios de distribución puedan ser consecuencia de diferentes dinámicas de reducción obliteradas. De esta forma, más de un $50 \%$ de los raspadores se abandonaron antes de alcanzar una reducción de 0,2 , siendo los casos de mayor reducción documentada en ambos niveles inferiores a 0,3 (Morales 2016).

\subsubsection{Macroutillaje}

Durante la excavación del nivel III se recuperaron dos plaquetas de esquisto en un contexto singular. Se hallaron juntas, una sobre la otra, dentro de un recodo formado por un bloque estructural del yacimiento y cubiertas, a su vez, por una lasca cortical de sílex de grandes dimensiones (Fig. 5). La disposición sugiere una intencionalidad en el depósito de estos elementos, relacionable con un escondite o cache.

Ambas plaquetas, dada su excepcionalidad y disposición se sometieron a un exhaustivo análisis microscópico para determinar su funcionalidad. Además, teniendo en cuenta las características del soporte y la posible existencia de grabados, se emplearon medios ópticos portátiles de bajos aumentos (Dino-lite digital microscope y PCE-MM200) y el microscopio digital Hirox KH-8700. Las gigafotos para la documentación gráfica de las modificaciones siguieron la propuesta metodológica de Vergès y Morales (2014), empleándose varios focos y sistemas de luz para identificar incisiones de escasa profundidad y realizar un calco digital.

Gracias a este procedimiento se identificó en una de ellas (Fig. 5-1) un conjunto de grabados muy erosionados, y uno mucho más profundo y continuo observable a simple vista (Fig. 5A). El estado de preservación no ha permitido por ahora identificar ninguna morfología específica ni rasgo figurativo. La plaqueta muestra estigmas y modificaciones superficiales de un momento de uso posterior, que pudieron afectar a algunas de las incisiones menos profundas. El borde exterior muestra un pulido generalizado, al que se le superponen estigmas de percusión en algunas zonas (Fig. 5B). En estas áreas pulidas se han documentado además estrías longitudinales. El borde de uno de los laterales está muy pulido y con una faceta muy marcada con estrías transversales (Fig. 5C).

La combinación de estas modificaciones indica funcionalidades diversas. La plaqueta en inicio pudo ser el soporte de algún tipo de manifestación gráfica, pero después tuvo varios usos. Los primeros estigmas de impacto se relacionan con el de percutor/retocador. En esta línea apuntan también las estrías longitudinales, que podrían estar relacionadas con su empleo como piedra abrasiva durante la talla. Finalmente, el pulido general y la faceta estriada se deberían a una actividad de raspado, probablemente de piel (Delgado-Raak 2011; Alvarez Soncini y Mansur 2017). Es decir esta plaqueta era un útil polifuncional (De Beaune 1994). 


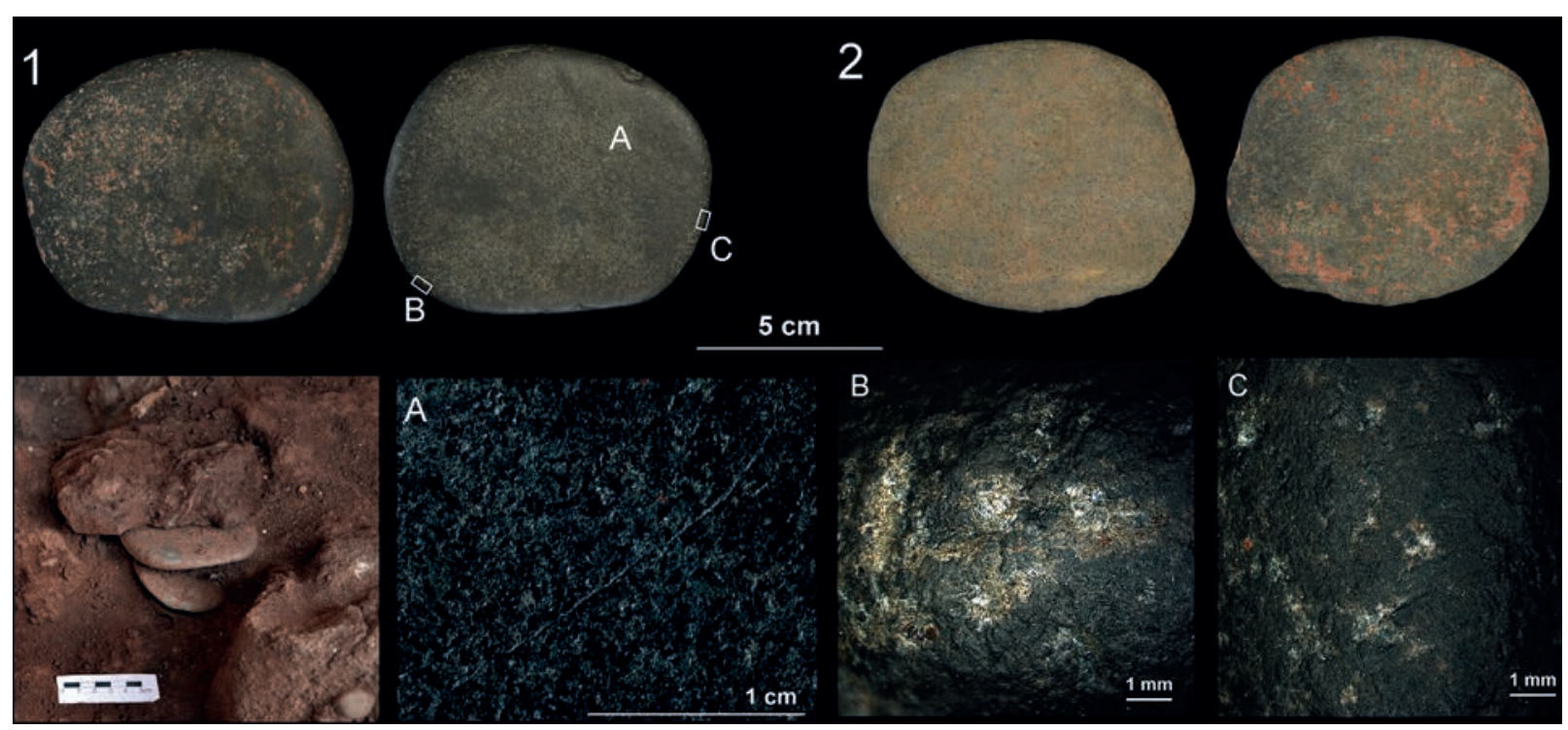

Fig. 5. Imágenes de las plaquetas de esquisto 1 y 2 del sector occidental del abrigo inferior de la Balma de la Vall procedentes del posible escondite documentado durante la excavación: A. detalle del conjunto de grabados erosionados; B. estigmas de percusión; C. estrías transversales en el borde pulido (en color en la edición electrónica).

El análisis de la segunda plaqueta, sin embargo, (Fig. 5-2) no identificó ninguna modificación por su posible empleo.

\subsection{La fauna}

El registro faunístico recuperado es escaso $(\mathrm{NR}=94)$. El Número de especímenes identificados (NISP) es de $10(10,6 \%)$. Cuando su atribución taxonómica fue imposible, los restos se asociaron a las distintas tallas de peso en relación al propio conjunto faunístico. $\mathrm{La}$ talla mediana se asocia con animales entre 100 y 300 $\mathrm{kg}$, representados en la lista taxonómica por ciervos (Cervus elaphus) y tal vez gamos (Dama dama); la pequeña integra animales entre 10 y $100 \mathrm{~kg}$ como cabras montesas (Capra pirenaica), rebecos (Rupicapra rupicapra), jabalís (Sus scrofa) y corzos (Capreolus capreolus). Finalmente, la muy pequeña con animales de menos de $10 \mathrm{~kg}$ engloba conejos (Oryctolagus cuniculus) y aves.

Atendiendo a la distribución en la secuencia, al nivel II pertenecen 13 restos: 3 especímenes (incisivo, fragmento de corona de molar y fragmento de mandíbula) pertenecen a la familia Cervidae (C. elaphus o $D$. dama). El resto se asocian a animales de talla mediana $(n=2)$ y pequeña $(n=3)$ o han sido clasificados como indeterminables $(\mathrm{n}=5)$.

El nivel III cuenta con la mayor parte del conjunto, 81 restos: 2 pertenecen a cérvidos de talla media, 4 a Leporidae, posiblemente Oryctolagus cuniculus, y
1 resto se atribuyó a un ave. La identificación de los demás $(n=74)$ no fue posible, aunque la mayoría se atribuyó a las tallas mediana y pequeña.

El análisis de la fracturación de los huesos indica el predominio de las fracturas en fresco (Villa y Mahieu 1991) al presentar planos curvos, ángulos oblicuos y superficies suaves. En tres huesos se atribuyeron a la acción de un carnívoro, y en otro, a alteración térmica. Como modificaciones superficiales se han observado cremaciones, marcas de dientes y de corte $\mathrm{y}$ vermiculaciones.

Ocho especímenes muestran evidencias de cremación, con coloraciones entre negro y blanco, incluyendo un caso de doble coloración (gris-blanca) y grados muy avanzados, que sugieren una cremación a elevadas temperaturas posterior al procesado de los huesos. Desconocemos si ésta fue intencionada.

Cuatro fragmentos de diáfisis de huesos largos de animales de talla media tienen marcas de dientes en forma de surcos y depresiones. Los surcos miden entre 0,13 y $0,71 \mathrm{~mm}$ de ancho, y las depresiones entre 1,79 y $3,44 \mathrm{~mm}$ de longitud y 1,36 y $2,03 \mathrm{~mm}$ de ancho. Estas medidas apuntan a la intervención de un carnívoro pequeño, posiblemente un cánido (zorro o lince) debido también a la fracturación de estos huesos. Únicamente un hueso largo de talla media con marcas oblicuas de corte localizadas en la diáfisis sugiere que se produjeron durante la descarnación. Estas marcas, además, presentan mordeduras superpuestas, que permiten secuenciar una primera actuación de los humanos sobre dicha carcasa. 


\section{DISCUSIÓN: EL CARÁCTER DE LAS OCUPACIONES}

Las nuevas excavaciones en la Balma de la Vall han permitido redefinir y profundizar en las ocupaciones humanas ya conocidas tras la primera fase de excavaciones, a inicios de los 1980. Una de las principales aportaciones de esta nueva fase ha sido la obtención de fechas absolutas para los contextos arqueológicos de las ocupaciones.

La escasa presencia de elementos datables, así como la mala preservación del material orgánico, han impedido obtener información cronológica de la secuencia completa. Solo el nivel III, la unidad de mayor entidad, ha podido ser fechado. Los resultados, tanto de TL como de C14 AMS son coherentes entre sí, y sitúan la formación de este nivel $c a 14.5 \mathrm{ka}$ cal BP. Las edades obtenidas y el componente tecno-tipológico son consistentes con la atribución del conjunto a los momentos finales del Magdaleniense superior final o inicios del Epimagdaleniense (Roman 2012). De esta forma la Balma de la Vall proporciona uno de los momentos de ocupación más antiguos de las montañas prelitorales del sur de Cataluña. Esta fecha a su vez proporciona un terminus ante quem para la formación del nivel IV, que por la escasez de materiales resulta de más difícil atribución, pese a que posiblemente no presente una distancia cronológica significativa respecto al nivel III. Los mismos argumentos pueden utilizarse para aproximar la cronología del nivel II. Por un lado, el dominio de los raspadores y elementos de dorso entre los configurados sigue la dinámica observada en todas las secuencias regionales fechadas entre finales del GS-2 e inicios del GI-1 (Morales et al. 2012). Por el otro, los esquemas de explotación laminar/microlaminar sobre lasca serían coherentes con la información disponible de yacimientos cercanos, especialmente la Cova de les Borres ${ }^{4}$, con una serie de ocupaciones del Magdaleniense superior final fechadas entre $13 \mathrm{y}$ 14 ka cal BP.

Los cuatro arqueoniveles, definidos en campo y refinados a partir de la proyección de los materiales, permiten dar una visión más compleja y precisa de las dinámicas de ocupación de la Balma de la Vall. El patrón de las ocupaciones que dieron lugar a los contextos arqueológicos de los niveles II, III y IV es similar y caracterizado por una escasa presencia de restos. Los valores absolutos de los elementos recuperados son dispares, pero siempre sensiblemente bajos. Los restos de sílex, p. ej., se reducen a 384 elementos

\footnotetext{
${ }^{4}$ Véase J. R. Rabuñal. La tecnología lítica del Magdaleniense superior final de la Cova de les Borres (La Febró): estudio morfotécnico $y$ definición de las estrategias de explotación. Universitat Rovira i Virgili de Tarragona, Tesis de Máster, 2016, 206 pp.
}

en el nivel II, 1120 en el nivel III, y 46 en el nivel IV. Ello implica densidades de 25 sílex $/ \mathrm{m}^{2}$ en el nivel II, de 75 sílex $/ \mathrm{m}^{2}$ en el nivel III, y de 3 sílex $/ \mathrm{m}^{2}$ en el nivel IV. En cambio, según los datos publicados por Vaquero (2004) para la base de la secuencia del Molí del Salt, los niveles B1 y B2, en la misma cronología que la Balma de la Vall, proporcionan densidades de 330 y 280 sílex $/ \mathrm{m}^{2}$ respectivamente.

La existencia de estos horizontes bien definidos y con esa escasez de restos plantea una dinámica de acumulación de materiales a partir de ocupaciones cortas y esporádicas reiteradas que formarían parte de un modelo de movilidad regional más complejo de los grupos de cazadores-recolectores magdalenienses del territorio. El entorno del yacimiento pudo constituir un lugar de frecuentación recurrente dada la abundancia de materias primas, y la Balma de la Vall un lugar para estancias breves y de baja intensidad.

Hay evidencias independientes concordantes con esta propuesta interpretativa. Por un lado, el estudio del aprovisionamiento de materia prima muestra un predominio de la captación de sílex bartoniense (tipo Tossa), aflorante en la cuenca del Francolí, en las proximidades del asentamiento $(0-10 \mathrm{~km})$. El sílex luteciense (tipos Maset y Morera) predomina en formaciones localizadas en las cuencas de los ríos Montsant y Siurana (21-27 km en línea recta). El sílex Vilaplana plantea como posibles áreas de aprovisionamiento los afloramientos localizados en la cuenca del Francolí (0-8 km respectivamente). Atendiendo a la representación de las materias primas, la cuenca del río Francolí aparece como el área de aprovisionamiento dominante y plantea radios de captación en torno a los $10 \mathrm{~km}$, asimilables con el radio de forrajeo de la ocupación. La distancia puede ampliarse hasta los $30 \mathrm{~km}$ si el aprovisionamiento de los sílex tipos Maset y Morera se produjese en las áreas con mayor abundancia de estos recursos y más alejadas del yacimiento (Montsant y Siurana).

Estas evidencias señalan un aprovisionamiento basado en la frecuentación de distintas cuencas en base a la captación en los afloramientos con mayor volumen de cada una de las variedades silíceas. Una dinámica que señalaría estrategias de aprovisionamiento selectivas respecto a la distribución natural de los recursos con una mayor frecuentación del área situada al este del yacimiento, sin descartar, aunque minoritarias, rutas en dirección noroeste (Soto 2015; Soto et al. s. f.).

Más allá de estos rasgos sobre la captación y gestión del sílex, la representación de las diferentes fases de la cadena operativa en cada tipo refuerza esta línea. Con independencia de su representación absoluta es relevante que haya tantas variedades de materia prima en conjuntos líticos tan reducidos, en especial si se considera el alto grado de fragmentación de las cadenas operativas. Esto queda en evidencia

Trab. Prehist., 75, N. ${ }^{\circ} 2$, julio-diciembre 2018, pp. 270-286, ISSN: 0082-5638

https://doi.org/10.3989/tp.2018.12215 
observando la distribución de las categorías estructurales en los diferentes tipos silíceos del nivel III, por contar con una mayor significación estadística. Al analizar la composición de los dos tipos mayoritarios se observa un comportamiento opuesto respecto al número de núcleos y retocados. En el caso del tipo Tossa (el $21 \%$ de todo el material), los núcleos son el $4 \%$, mientras que en el tipo Masset (30\%), no se ha documentado ninguno. En los retocados, sin embargo, los tipos Masset y Tossa tienen un $7 \%$ y un $2 \%$ respectivamente. Esta dinámica se acentúa todavía más observando las variedades minoritarias. El sílex tipo Vilaplana presenta un $28 \%$ de núcleos (sobre un total de 8 elementos), mientras el porcentaje de retocados en las dos variedades del tipo Morera se acerca al $30 \%$ (sobre 53 restos).

Esta gestión diferencial de las variedades silíceas cobra sentido a nivel territorial. El predominio de los núcleos tipo Tossa y Vilaplana confirma el aprovisionamiento en las áreas más próximas, y su introducción y talla en el yacimiento en momentos iniciales de la cadena operativa. La abundancia de retocados sobre los tipos Masset y Morera, predominantes en áreas más alejadas, podría justificar su introducción como productos ya elaborados.

El alto grado de fragmentación de las cadenas operativas es un modelo contrario al esperado en un escenario de estabilidad ocupacional. En ocupaciones con un carácter residencial más definido, el factor tiempo y la acumulación de actividades generarían una representación más homogénea de las categorías estructurales en las materias primas talladas en el yacimiento, existiera o no una cierta gestión diferencial de las mismas (Ingbar 1994; Hayden et al. 1996).

A parte del estudio de las cadenas operativas, la información de uso y gestión de los útiles también presenta cuestiones interesantes sobre el carácter de las ocupaciones. El análisis de la reducción muestra un patrón claro, caracterizado por un uso mínimo de los raspadores. Estos son abandonados poco después de su fabricación, manteniendo todavía un potencial de uso muy elevado. Estos datos contrastan claramente con lo observado en yacimientos de la región, como la Cativera (Fontanals, Ollé et al. 2009; Morales et al. 2013; Fontanals, Vergès et al. 2014), donde se ha observado que un $45 \%$ de los raspadores estudiados muestra al menos una fase de reavivado previa a su abandono (Morales y Vergès 2014). Los valores de reducción en este caso son algo superiores a los documentados en la Vall: 0,26 contra 0,18 y 0,21 . Los niveles B1 y B2 del Molí del Salt muestran índices de reducción de 0,26 y 0,4 respectivamente. Las ocupaciones de la Cova de les Borres proporcionan valores de $0,24,0,25$ y 0,36 en el tramo superior, y de 0,41 en las ocupaciones más antiguas, sincrónicas a las de la
Vall. Como contrapunto, el estudio de los raspadores de El Cavet, un poblado neolítico con ocupaciones que se suponen más estables y duraderas proporciona un índice de 0,6 (Morales 2016). Independientemente de su grado de reducción, en este contexto de ocupaciones de corta o muy corta duración es destacable el alto porcentaje de raspadores, un útil presumiblemente relacionado con actividades de carácter doméstico. El avance de los estudios funcionales aportará más datos para tratar este aspecto. Sin embargo, hay que tener en cuenta que, sea cual sea el contexto, este morfotipo es predominante en todas las ocupaciones fechadas en el Tardiglaciar.

Los patrones de reducción refuerzan la idea de ocupaciones breves y esporádicas, donde la industria elaborada se abandona al finalizar las ocupaciones con una tasa de utilización baja. Este esquema ayuda a plantear el modelo ocupacional definido en los patrones de movilidad de los cazadores-recolectores (Binford 1990; Kelly 2007) y relacionado con accesos logísticos de grupos pequeños para el aprovisionamiento de recursos específicos. Generalmente, estas ocupaciones son recurrentes, acumulando en el registro los restos de breves frecuentaciones reiteradas a lo largo del tiempo. Binford (1980) define los lugares donde ocurren estas ocupaciones como locations, localidades de aprovisionamiento al por menor de recursos con una alta demanda o valor, y donde el uso, agotamiento y abandono de herramientas se produce en una tasa muy baja, tal y como ocurre en la Balma de la Vall.

Otra característica de esas ocupaciones es la disposición o almacenamiento de kits de seguridad (insurance gear) que se distribuyen por el territorio en previsión de visitas futuras formando pequeños depósitos o caches (Binford 1979). Las dos plaquetas de esquisto y la lasca de sílex del nivel III de la Balma de la Vall pueden ser un ejemplo de estos kits. La asociación y disposición de estos elementos sugiere que fueron almacenados de forma intencional. En un primer momento una de las plaquetas pudo haber sido el soporte de algún tipo de manifestación gráfica, pero en sus últimas fases se usó para el trabajo de las pieles y la talla. La gran lasca de sílex supone una reserva de materia prima en caso de necesidad futura, y las dos plaquetas son herramientas versátiles utilizables para diferente tipo de actividades.

\section{CONCLUSIONES}

La Balma de la Vall es una nueva evidencia de la ocupación humana durante el Paleolítico superior final en las Montañas de Prades. Hasta el momento, la primera ocupación visible arqueológicamente de este territorio parece situarse al final del Dryas antiguo / inicios del 
GI-1, hace unos 15.000 años cal BP. Este momento de ocupación se documenta en yacimientos, como el Abric dels Colls y l'Hort de la Boquera, en la cuenca del Montsant, la Cova de les Borres y el Molí del Salt, en el entorno de las Montañas de Prades, o la Cova de la Guineu, en la cuenca del río Foix.

Estas ocupaciones preceden a un incremento en el número de yacimientos $\mathrm{y}$ en las evidencias de ocupación, situadas en torno al $13.000 \mathrm{cal} \mathrm{BP}$, y representan un aumento en la demografía y en la estructuración social y económica del territorio. Gran parte de las secuencias del Molí del Salt, la Cova de les Borres o el Abric del Filador se corresponden grosso modo con este episodio.

Dentro de esta fase pionera de ocupación prelitoral, la Balma de la Vall es un ejemplo de ocupaciones de baja intensidad. Las características del registro conducen a interpretar su formación como producto de una reiteración de ocupaciones esporádicas de corta duración, posiblemente relacionadas con episodios de movilidad de grupos reducidos para el aprovisionamiento de recursos específicos. Este patrón muestra una dinámica opuesta a lo observado en los niveles inferiores del Molí del Salt y de la Cova de les Borres, donde los estudios indicaría un carácter más residencial de las ocupaciones.

Este modelo dual, con asentamientos residenciales y estaciones logísticas, establece una dinámica de movilidad compleja, determinada por factores como el aprovisionamiento de materia prima y el tamaño de los grupos que ocupan los diferentes asentamientos. Sería interesante profundizar en una visión más detallada de estos eventos, a través del análisis funcional de los conjuntos líticos, para discernir que detalles caracterizan cada uno de los asentamientos. Aunque la escasez y mala preservación del registro faunístico impiden por el momento aproximarse a variables significativas como la estacionalidad de las ocupaciones.

Además de los análisis funcionales, actualmente en curso, planteamos un futuro análisis de los patrones de asentamiento regionales que identifique si hubo o no ciclos anuales de movilidad donde las ocupaciones residenciales y logísticas identificadas tengan espacios diferentes, o si por el contrario nos hallamos ante visiones diversas de un mismo patrón ocupacional. Un aspecto interesante para abordar esta problemática puede ser comparar ocupaciones en asentamientos de montaña con las de los asentamientos litorales, cómo serían el Camping Salou (Roman et al. 2016), la Cativera (Morales et al. 2013) o la Balma de la Griera (Fullola et al. 1997). Esta línea permitiría observar la existencia de patrones de ocupación o estrategias de gestión territorial diferentes en función de la localización geográfica de los asentamientos dentro de un mismo ámbito regional.

\section{AGRADECIMIENTOS}

Los autores agradecen el esfuerzo y dedicación a los participantes de la excavación, y en especial Maties Solé, Josep M. Fullola, Jordi Nadal, María Adserias y miembros del Museu-Arxiu de Montblanc, por su disposición plena en los momentos iniciales y durante el desarrollo de esta investigación.

\section{BIBLIOGRAFÍA}

Adserias, M. y Solé, M. 1994: "L'ocupació paleolítica de la Balma de la Vall (Montblanc, Conca de Barberà)". Aplec de Treballs 12: 59-68.

Alvarez Soncini, M. C. y Mansur, M. E. 2017: "Pecked and polished materials from southern Patagonia: An experimental techno-functional approach". Quaternary International 427, Part B: 66-73. https://doi.org/10.1016/j.quaint.2015.12.051

Angelucci, D. E. 2003: "Geoarchaeology and micromorphology of Abric de la Cativera (Catalonia, Spain)". Catena 54: 573-601. https://doi.org/10.1016/s0341-8162(03)00132-2

Arbey, F. 1980: "Les formes de la silice et l'identification des evaporites dans les formations silicifiees". Bulletin des Centres de Recherches Exploration-Production Elf-Aquitaine 4: 309-365.

Bathrust, R. G. 1975: Carbonates Sediments and their diagenesis. Elsevier. Amsterdam.

Binford, L. 1979: "Organization and formation processes: looking at curated technologies". Journal of Anthropological Research 35, 3: 225-273. https://doi.org/10.1086/jar.35.3.3629902

Binford, L. 1980: "Willow smoke and dog's tails: hunter-gatherer settlement systems and archaeological site formation". American Antiquity 45, 1: 4-20. https://doi.org/10.2307/279653

Binford, L. 1990: "Mobility, housing, and environment: a comparative study". Journal of Anthropological Archaeology 46: 119-152. https://doi.org/10.1086/jar.46.2.3630069

Boggs, J. S. 2009: Petrology of sedimentary rocks. Cambridge University Press. Cambridge.

De Beaune, S. 1994: "Multifunctionality of pebbles used in the Upper Palaeolithic: an ethnographic approach". Bulletin of Primitive Technology 8: 64-67.

Delgado-Raak, S. 2011: "La utilización de cantos rodados y plaquetas en la secuencia estratigráfica de Santimamiñe". En J. C. López Quintana (ed.): La cueva de Santimamiñe: revisión y actualización (2004-2006). Kobie Serie Bizkaiko Arkeologi Indusketak: 171-196.

Domènech, E. M. 1998: "Los sistemas de producción lítica del Paleolítico superior final y Epipaleolítico en la vertiente mediterránea. Tres ejemplos claves: la Grotte Gazel (Salelles-Cabradés, Aude), Cova Matutano, Vilafamés, Castelló) y Abric del Filador (Margalef de Montsant, Tarragona)". Pyrenae 29: 9-45.

Fontanals, M.; Ollé, A. y Vergès, J. M. 2009: "Les ocupacions del tardiglacial a l'Abric de la Cativera (El Catllar, Tarragonès)". En O. Mercadal (ed.): Els Pirineus $i$ les àrees circumdants durant el tardiglacial. Mutacions i filiacions tecnoculturals, evolució paleoambiental (16000-10000 BP). Homenatge al professor Georges Laplace. XIV Col·loqui Internacional d'Arqueologia de Puigcerdà (Girona 2006): 537-547. Puigcerdà.

Fontanals, M., Vaquero, M. y Vergès, J. M. 2006. "Noves dades sobre el paleolític superior al sud de Catalunya: El Molí del Salt (Vimbodí, Conca de Barberà) i La Cativera (El Catllar, Tarragonès)". Quadern de Treball 14: 43-68.

Fontanals, M.; Vergès, J. M. y Morales, J. I. 2014: “La Cativera (El Catllar, Tarragona). Aportaciones al límite Pleistoceno-Holoceno en el sur de Cataluña". En R. Sala (ed.): Los cazadores recolectores del Pleistoceno y del Holoceno en Iberia y el estrecho de Gibraltar: estado actual del conocimiento del registro arqueológico. Universidad de Burgos, Fundación Atapuerca. Burgos: 236-238.

Fullola, J. M. 1983-1984: "Estat actual del coneixement de la Prehistòria a la vall del Montsant”. Tribuna d'Arqueologia 1983-1984: 7-14. 
Fullola, J. M.; Bartrolí, R.; Cebrià, A.; Bergadà, M.; Nadal, J. y Estrada, A. 1997: "El Epipaleolítico en la Balma de la Griera (Calafell, Baix Penedès, Tarragona) en el contexto del NE peninsular". En P. Bueno y R. Balbín (eds.): II Congreso de Arqueología Peninsular (Zamora 1996) 2: 327-348. Zamora.

Fullola, J. M. y García-Argüelles, P. 2006: "La Cueva del Parco (Alós de Balaguer, Lleida) y el Abrigo del Filador (Margalef de Montsant, Tarragona): dos secuencias clave para el conocimiento del epipaleolítico en el nordeste peninsular". En A. Alday (ed.): El Mesolítico de muescas y denticulados en la cuenca del Ebro y el litoral mediterráneo peninsular. Diputación Foral de Alava. Alava: 121-133.

García, M.; Rosell, J.; Vallverdú, J. y Vergès, J. M. 1996: "L'abric de Picamoixons i les etratègies dels darrers caçadors recol-lectors epipaleolíticos". Quaderns de Vilaniu 29: 91-100.

García, M.; Rosell, J.; Vallverdú, J. y Vergès, J. M. 1997: "La plaqueta pintada del yacimiento Epipaleolítico de Picamoixons (Alt Camp, Tarragona): aproximación al estudio de la cadena operativa". Pyrenae 28: 25-40.

García, M. y Vaquero, M. 2006: “La variabilité graphique du Molí del Salt (Vimbodí, Catalogne, Espagne) et l'art mobilier de la fin du Paléolithique supérieur à l'est de la Péninsule Ibérique". L'Anthropologie 110: 453-481. https://doi.org/10.1016/j.anthro.2006.07.009

García-Argüelles, P. 2004: "Epipaleolithic Phases in the Northeast of the Iberian Península". En M. González Morales y G. A. Clark (eds.): The Mesoltihic of the Atlantic fFaçade: Proceedings of the Santander Symposium. Arizona State University. Santander: 11-120.

García-Argüelles, P.; Adserias, M.; Bartrolí, R.; Bergadà, M.; Cebrià, A.; Doce, R.; ... y Viñas, R. 1992: "Síntesis de los primeros resultados del programa sobre Epipaleolítico en la Cataluña central y meridional". En P. Utrilla (ed.): Aragón/Litoral mediterráneo. Intercambios culturales durante la Prehistoria. Institución Fernando el Católico. Zaragoza.

García-Argüelles, P.; Fullola, J. M.; Román, D.; Nadal, J. y Bergadà, M. 2013: "El modelo epipaleolítico geométrico tipo Filador cuarenta años después: vigencia y nuevas propuestas". En M. de la Rasilla (ed.): F. Javier Fortea Pérez. Universitatis Ovetensis Magister. Estudios en homenaje. Ediciones de la Universidad de Oviedo. Oviedo: 151-165.

García-Argüelles, P.; Nadal, J. y Fullola, J. M. 2005: “El abrigo del Filador (Margalef de Montsant, Tarragona) y su contextualización cultural y cronológica en el Nordeste peninsular". Trabajos de Prehistoria 62 (1): 65-84. https://doi.org/10.3989/tp.2005.v62.i1.56

García-Argüelles, P.; Nadal, J.; Fullola, J. M.; Bergadà, M. M.; Domingo, I.; Allué, A. y Lloveras, L. 2014: "Nuevas interpretaciones del Paleolítico Superior Final de la Cataluña meridional: el yacimiento de L' Hort de la Boquera (Priorat, Tarragona)". Trabajos de Prehistoria 71(2): 242-260. https://doi.org/10.3989/tp.2014.12133

García Catalán, S. 2007: "La industria lítica del nivel ASup del Molí del Salt (Vimbodí, Tarragona) y su contextualización en el Paleolítico superior final de la vertiente mediterránea de la Península Ibérica". Trabajos de Prehistoria 64(2): 157-168. https://doi.org/10.3989/tp.2007.v64.i2.114

García Catalán, S.; Vaquero Rodríguez, M.; Pérez Goñi, I.; Menéndez Iglesias, B.; Peña García, L.; Blasco López, R.; ...y Muñoz Encinar, L. 2009: "Palimpsestos y cambios culturales en el límite PleistocenoHoloceno: el conjunto lítico de Picamoixons (Alt Camp, Tarragona)", Trabajos de Prehistoria 66, 2: 7-22. https://doi.org/10.3989/tp.2009.0919

García-Catalán, S.; Gómez de Soler, B.; Soto, M. y Vaquero, M. 2013: "Los sistemas de producción lítica en el Paleolítico superior final: el caso del nivel ASUP del Molí del Salt (Vimbodí i Poblet, Tarragona)". Zephyrus LXXII, 2: 39-58. https://doi.org/10.14201/zephyrus2013723958

Hayden, B.; Franco, N. y Spafford, J. 1996: "Evaluating Lithic Strategies and Design Criteria". En G. Odell (ed.): Stone tools: theoretical insights into human Prehistory. Plenum Press. New York: 9-47.

Ingbar, E. E. 1994: "Lithic material selection and technological organization". En P. J. Carr (ed.): The organization of North American Prehistoric Chipped Stone Tool Technologies. International Monographs in Prehistory, Archaeological Series 7. Ann Arbor: 45-56.

Kelly, R. L. 1983: "Hunter-gatherer Mobility Strategies". Journal of Anthropological Research 39: 277-306. https://doi.org/10.1086/jar.39.3.3629672
Kelly, R. L. 1992: "Mobility/sedentism: Concepts, archaeological measures, and effects". Annual Review of Anthropology 21: 43-66. https://doi.org/10.1146/annurev.anthro.21.1.43

Kelly, R. L. 2007: The Foraging Spectrum: Diversity in Hunter-Gatherer Lifeways. Percheron Press. New York.

Kendall, A. C. 1979: "Facies Models 12. Subacqueous evaporites". Geoscience Canada 5, 3: 124-139.

LAUT 1992: Picamoixons. Un assentament estratègic dels darrers caçadors recol-lectors. Museu d'Història de Tarragona. Tarragona.

Morales, J. I. 2015: La reducción de la industria lítica: aproximación a los patrones de asentamiento y movilidad de los grupos paleolíticos. Universitat Rovira i Virgili. Tarragona. http://hdl.handle.net/10803/348555

Morales, J. I. 2016: "Distribution patterns of stone-tool reduction: Establishing frames of reference to approximate occupational features and formation processes in Paleolithic societies". Journal of Anthropological Archaeology 41: 231-245. https://doi.org/10.1016/j.jaa.2016.01.004

Morales, J. I.; Burjachs, F.; Allué, E.; Fontanals, M.; Soto, M.; Expósito, I.; ...e Yll, E. Y. 2012: "Paleogeografía humana durante el Tardiglaciar y Holoceno inicial en el ámbito mediterráneo del NE Ibérico". En F. Burjachs y V. Turu (eds.): Cambios climáticos vs cambios tecnológicos-culturales: las transiciones Paleolítico Superior final Mesolítico -Neolítico antiguo en el NE de Iberia. Cuaternario $y$ Geomorfologia 26, 3-4: 11-28.

Morales, J. I.; Lorenzo, C. y Vergès, J. M. 2015: "Measuring retouch intensity in lithic tools: a new proposal using 3D scan data". Journal of Archaeological Method and Theory 22, 2: 543-558. https://doi.org/10.1007/s10816-013-9189-0

Morales, J. I.; Soto, M.; Lorenzo, C. y Vergès, J. M. 2015: “The evolution and stability of stone tools: the effects of different mobility scenarios in tool reduction and shape features". Journal of Archaelogical Science: Reports 3: 295-305. https://doi.org/10.1016/j.jasrep.2015.06.019

Morales, J. I. y Vergès, J. M. 2014: "Technological behaviors in Paleolithic foragers. Testing the role of resharpening in the assemblage organization". Journal of Archaeological Science 49, 0: 302-316. https://doi.org/10.1016/j.jas.2014.05.025

Morales, J. I.; Vergès, J. M.; Fontanals, M.; Ollé, A.; Allué, E. y Angelucci, D. E. 2013: "Procesos técnicos y culturales durante el Holoceno inicial en el noreste de la Península Ibérica. Los niveles B y Bb de La Cativera (El Catllar, Tarragona)". Trabajos de Prehistoria 70 (1): 54-75. https://doi.org/10.3989/tp.2013.12102

Nadal, J. 1994: "Estudi faunístic de la balma de la Vall (Montblanc, Conca de Barberà)". Aplecs de Treballs del Centre d'Estudis de la Conca de Barberà 12: 69-75.

Roman, D. 2012: "Nouveautés sur la séquence du Pléistocène final et l'Holocène initial dans le versant méditerranéen de la péninsule Ibérique à travers l'industrie lithique". L'Anthropologie 116, 5: 665-679. https://doi.org/10.1016/j.anthro.2012.09.002

Roman, D. ; Nadal, J. ; Domingo, I. ; García-Argüelles, P. ; Lloveras, L. y Fullola, J. M. 2016: "La fin du Paléolithique dans la Catalogne méridionale ibérique revisitée : nouvelles réponses pour anciennes questions". L'Anthropologie 120, 5: 610-628 https://doi.org/10.1016/j.anthro.2016.10.001

Shott, M. 2002: "Weibull estimation on use life distribution in experimental spear-point data". Lithic Technology 27, 2: 93-109. https://doi.org/10.1080/01977261.2002.11720993

Shott, M. y Sillitoe, P. 2004: "Use-life distributions in archaeology using New Guinea Wola ethnographic data". American Antiquity 69, 2: 339-355. https://doi.org/10.2307/4128424

Sonnefeld, P. 1979: "Brines and evaporites". Geoscience Canada 6, 2: 83-90

Soto, M. 2015: Áreas y estrategias de aprovisionamiento lítico de los últimos cazadores-recolectores en las Montañas de Prades (Tarragona). Universitat Rovira i Virgili. Tarragona. http://hdl.handle.net/10803/348554

Soto, M.; Gómez de Soler, B. y Vallverdú, J. s. f.: "The chert abundance ratio (CAR): a new parameter for interpreting Palaeolithic raw material procurement". Archaeological and Anthropological Science. https://doi.org/10.1007/s12520-017-0516-3 [En línea: 1 de julio 2017]

Soto, M.; Gómez de Soler, B.; Vallverdú, J. y Vaquero, M. 2014: "Potential siliceous sources during Prehistory: Results of prospecting in 
the East margin of the Ebro Basin (NE Iberian Peninsula)". Journal of Lithic Studies 1, 1: 293-318. https://doi.org/10.2218/jls.v1i1.772

Tucker, M. y Wright, P. 1990: "Carbonate depositional systems I: marine shallow-water and lacustrine carbonates". En J. Wiley and Sons Ltd (eds.): Carbonate sedimentology. Blackwell Science. Oxford.

Vallverdú, J.; Soto, M.; Morales, J. I.; Saladié, P.; Gomis, S. y Viñas, R. 2014: "Les intervencions arqueològiques a la Balma de la Vall durant els anys 2011 fins 2013 (Rojals-Montblanc, Conca de Barberà)". Podall 3: 7-23.

Vaquero, M. (coord.) 2004: Els darrers caçadors-recolectors de la Conca de Barberà: el jaciment del Moli del Salt (Vimbodí). Excavacions 1999-2003. Museu Arxiu de Montblanc i Comarca. Montblanc.

Vaquero, M.; Allué, E.; Alonso, S.; Campeny, G.; Estrada, A.; García M.;... y Vilalta, J. 2005: "Una nueva secuencia del Paleolítico Superior final en el Sur de Cataluña: el Molí del Salt (Vimbodí, Tarragona)". En N. Ferreria (ed.): O Paleolítico. Actas do IV Congresso de Arqueologia Peninsular (Faro 2004): 493-508. N. Faro.

Vaquero, M.; Alonso, S.; García-Catalán, S.; García-Hernández, A.; Gómez de Soler, B.; Rettig, D. y Soto, M. 2012: "Temporal nature and recycling of Upper Paleolithic artifacts: the burned tools from the Molí del Salt site (Vimbodí i Poblet, northeastern Spain)". Journal of Archaeological Science 39, 8: 2785-2796. https://doi.org/10.1016/j.jas.2012.04.024

Vergès, J. M. y Morales J. I. 2014: “The gigapixel image concept for graphic SEM documentation. Applications in archeological use-wear studies". Micron 65, 0: 15-19.

https://doi.org/10.1016/j.micron.2014.04.009
Vila, P. y Mahieu, E. 1991: "Breakage patterns of human long bones". Journal of Human Evolution 20: 1-22. https://doi.org/10.1016/0047-2484(91)90034-s

Vilaseca, S. 1949: "Avance al estudio de la cueva del Filador, de Margalef (Provincia de Tarragona)". Archivo Español de Arqueologia 77: 347-361.

Vilaseca, S. 1953: Las industrias del sílex tarraconenses. Consejo Superior de Investigaciones Científicas, Instituto Rodrigo Caro. Madrid.

Virgili, C. 1958: El Triásico de los Catalánides. Instituto Geológico y Minero de España. Madrid.

\section{ARCHIVOS COMPLEMENTARIOS}

En la versión en línea pueden encontrarse adjunto un archivo en formato PDF, con la imagen macroscópica y láminas delgadas de los sílex.

$\mathrm{AC} 1$ : Sector occidental del abrigo inferior de la Balma de la Vall, campañas de 2011-2013. Imagen macroscópica y láminas delgadas de los sílex. A. Tossa 1; B. Tossa 2; C. Maset 2; D. Maset 3; E. Morera 1; F. Morera 2; G. Vilaplana 1; H. Vilaplana 2. a-d. Láminas delgadas (luz plana polarizada; luz polarizada cruzada). 


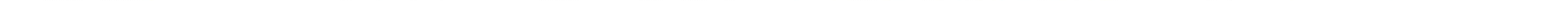

